International Journal of Poultry Science 9 (5): 490-494, 2010

ISSN 1682-8356

(C) Asian Network for Scientific Information, 2010

\title{
Assessing the Seroprevalence Against Avian Pneumovirus and Ornithobacterium rhinotracheale in Broilers in Uruguay
}

\author{
K. Suzuki', M. Petruccelli', G. Rodríguez ${ }^{2}$, G. Trenchi ${ }^{2}$, G. Giossa ${ }^{2}$ and H. Trenchi ${ }^{2}$ \\ 'Laboratorio de Diagnóstico de Enfermedades de las Aves y los Pilíferos, \\ Facultad de Ciencias Veterinarias, Universidad Nacional de La Plata, Argentina \\ ${ }^{2}$ Área de Patología y Producción Avícola, Facultad de Veterinaria, \\ Universidad de la República, Montevideo, Uruguay
}

\begin{abstract}
The objective of this study was to estimate the true prevalence of individual chickens serologically test-positive against avian pneumovirus and Ornithobacterium rhinotracheale in Uruguay. Seventeen different broiler farms existed in three different provinces in Uruguay were recruited and the 1861 broilers were investigated. Individual-chicken sera were analyzed using a commercial enzyme-linked immunosorbent assay. The overall true seroprevalence was 1.9\% [95\% Bayesian Credible Interval (BCl): $<1-7.4 \%$ ] and less than $0.1 \%(95 \% \mathrm{BCl}: 0-<0.1 \%)$ against avian pneumovirus and Ornithobacterium rhinotracheale, respectively. The result seroprevalence was relatively lower than that reported by other authors in a neighbouring country Argentina where the infection of these diseases was recently observed. This difference was discussed.
\end{abstract}

Key words: APV, bayesian model, ORT

\section{INTRODUCTION}

Respiratory diseases have historically been a major concern in commercial poultry production. A variety of pathogens has been identified as causing respiratory disease, acting either in a primary or secondary part. Avian pneumoviruses can lead to damage to the upper respiratory tract, such as, lack of cilia movement and/or cilia loss; damage that may lead to respiratory clinical signs such as coughing, sneezing, swollen head and more complexed respiratory troubles (Cook et al., 1988; Cook, 2000; Cook and Cavanagh, 2002; Gough, 2005). On the other hand, Ornithobacterium rhinotracheale has been connected with respiratory signs and growth retardation, in combination with increased mortality, fibrinopurulent pneumonia and airsaculitis. Increases in veterinary costs, increases in condemnation rate, drops in egg production, reduction of eggshell quality and decreased hatchability have been reported (Bisgaard et al., 2008; Van Empel et al., 2008). In Uruguay, seroprevalence of avian pneumovirus (Giossa et al., 2010) and Ornithobacterium thinotracheale (Suzuki et al., 2010) infections at flock-level have been reported. To our knowledge, no report of seroprevalence of these infections at individual-chicken level in Uruguay has been publicized. The objective of this study was to estimate the True Prevalence (TP) of individual chickens serologically test-positive against avian pneumovirus and Ornithobacterium rhinotracheale in Uruguay, using Bayesian inference.

\section{MATERIALS AND METHODS}

Study area: Uruguay is located in the south-eastern part of South America, having a poultry population of 16 million, a poultry meat production of 76,000 tonnes per year and a poultry egg production of 53,500 tonnes per year (FAO, 2010). The south of the country including the capital city Montevideo and Canelones Department has the concentration of chicken population (about $90 \%$ of the total), because of in-and-around the big market Montevideo (Ministerio de Ganaderia Agricultura y Pesca, 2010).

Sample collection: Seventeen farms of broilers aged older than 35 days were studied. Each study broiler was randomly selected at different farms selected from the capital city Montevideo, Canelones and Lavalleja (east of Canelones) Departments. None of the broilers had been inoculated against avian pneumovirus and Ornithobacterium rhinotracheale prior to sampling. The required sample size of 1537 in total from a chicken population of 16 million was sufficient to obtain a $95 \%$ confidence interval $(95 \% \mathrm{Cl})$ with a desired precision of $\pm 2.5 \%$ when the estimated AP was $50 \%$ (Hintze, 2008). The sample size in each of the farms was proportionally assigned ( $1 \%$ each of the total number of broilers at study farms) by the attainable financial, human and material means. The field study was conducted between October 2008 and April 2009, comprised data collection through questionnaire interviews for each farm selected, 
together with blood sample collections for each broiler (questionnaire results were not treated with hereinafter).

Laboratory examinations: Blood samples were used for diagnostic tests. Individual-chicken sera were analyzed using a commercial Enzyme-Linked Immunosorbent Assay (ELISA) for the detection of antibody against avian pneumovirus and Ornithobacterium rhinotracheale (FlockChek@) Avian Pneumovirus Antibody Test Kit and FlockChek® Ornithobacterium rhinotracheale Antibody Test Kit, Dr Bommeli AG, a subsidiary of IDEXX Laboratories, Liebefeld-Bern, Switzerland). Positive and negative controls were included for each assay. Absorbance was read on an ELISA reader at $650 \mathrm{~nm}$. Based on the instruction manual of the ELISA kits, serum samples with Sample to Positive (S/P) ratios greater than 0.2 (titres larger than 396) and 0.4 (titres greater than 844) for avian pneumovirus and Ornithobacterium rhinotracheale, respectively were considered seropositive.

Data analysis: Data were entered into a database using the Base in the OpenOffice.org software version 3.1.1 (Sun Microsystems, Santa Clara, CA, USA). Seroprevalence estimates based on the use of an imperfect test, which is a nature of ELISA tests, must be corrected to take account of test performance. Based on the published ELISA specificity values $[0.98 \quad(=602$ samples test-negative out of 612 samples true-negative) and 1.00 (= 40 samples test-negative out of 40 samples true-negative)] for avian pneumovirus and Ornithobacterium rhinotracheale, respectively (IDEXX, 2003,2004 ) and the expert's opinion to ELISA sensitivity for both the diseases (the most likely value for the sensitivity is 0.98 and $95 \%$ sure that the value exceeds 0.95) (IDEXXJProduction Animal Services, 2009, Personal Communication), estimated TP of antibodies among study broilers at each farm were calculated. TPs for each farm were derived from the Apparent Prevalence (AP) using the Rogan-Gladen estimator (Rogan and Gladen, 1978) and information about the Sensitivity (Se) and Specificity $(S p)$ :

$$
T P=(A P+S p-1) /(S e+S p-1)
$$

A Bayesian hierarchical model was used to derive posterior Bayesian estimates (denoted TPB, $\mathrm{Se}_{\mathrm{B}}$ and $\mathrm{SpB}_{\mathrm{B}}$ mentioned below) from prior distributions and the data from each broiler farm in this study. Consider estimation of the infection seroprevalence for a single farm where y broilers tested positive out of $n$ broilers randomly selected. If the sample size $(N)$ is much larger than $n$, then the sampling distribution of $y$ is approximately binomial:

$$
y \mid \mathrm{TP}_{\mathrm{B}}, \mathrm{Se}_{\mathrm{B}}, \mathrm{Sp}_{\mathrm{B}} \sim \operatorname{Binomial}(\mathrm{n}, \mathrm{AP})
$$

Where TPв is the true seroprevalence of infection in the samples and $\mathrm{Se}_{\mathrm{e}}$ and $\mathrm{Sp}_{\mathrm{B}}$ are the sensitivity and specificity, respectively, of the diagnostic test applied to each broiler sampled and AP $=\mathrm{TPB}^{*} \mathrm{Se}_{\mathrm{B}}+(1-\mathrm{TP})(1-$ $S p B)$. The authors modeled uncertainty about the Seв and $\mathrm{Sp}$ e of the diagnostic test using independent beta prior distributions (Vose, 2008):

$$
\begin{aligned}
& S_{в} \sim \operatorname{Beta}(d+1, n-d+1) \\
& S_{p} \sim \operatorname{Beta}(d+1, n-d+1)
\end{aligned}
$$

Where $d$ is the number of desired (positive or negative) outcomes and $n$ is the number of samples tested per farm. These values were decided by using the Se and $S p$ values for avian pneumovirus and Ornithobacterium rhinotracheale mentioned above. Especially for obtaining Ses values for the two diseases, BetaBuster software (http://mww.epi.ucdavis.edu/diagnostictests/ betabuster.html) was used and the values " $d+1$ " and " $n$ - $d+1$ "were produced as output. A beta distribution provides a flexible means of modeling uncertainty about parameters ranging between 0 and 1 (Baadsgaard and Jogensen, 2003).

At the second level of the hierarchy, the model was to assume that percentage of test positive were alike in some way. This was equal to specifying a random effects model for the true seroprevalence probability $\mathrm{p}_{\mathrm{i}}$ as follows. They were assumed to be drawn from a common Normal population distribution:

$$
\begin{gathered}
\operatorname{logit}\left(p_{i}\right)=b_{i} \\
b_{i} \sim \operatorname{Normal}(\mu, \tau)
\end{gathered}
$$

A standard non-informative prior is then specified for the population mean (logit) or probability of overall seroprevalence, $\mu$, with an alternative non-informative prior considered for the random effects variance (a uniform prior on the standard deviation), because of the absence of strong prior information:

$$
\begin{gathered}
\sigma \sim \text { Uniform }(0,100) \\
\tau=1 / \sigma^{2}
\end{gathered}
$$

The true seroprevalence probability and associated $95 \%$ Bayesian Credible Intervals (BCls) were computed via the Gibbs sampler, a Markov chain Monte Carlo (MCMC) technique, which was implemented using WinBUGS software (Lunn ef al., 2000). The exponential of these 
true seroprevalence probabilities was taken to obtain overall seroprevalence estimates (Prev) and their 95\% $\mathrm{BCls:}$

$$
\begin{gathered}
\text { Prev }=\exp (\mu) /(1+\exp (\mu)) \\
\mu \sim \text { Normal }(0.0,1.0 \mathrm{E}-6)
\end{gathered}
$$

Results presented here were based on multiple runs of length 100,000 following a burn-in of 10,000 iterations to achieve convergence.

\section{RESULTS}

The 1861 chickens investigated accounted for about $1 \%$ of the study chicken population and $0.01 \%$ of the total chicken population in Uruguay. All individual-chicken sera from the study area representing 17 farms were examined with the ELISA. Of all, $0.4 \%$ of the serum samples had test-positive against both avian pneumovirus and Ornithobacterium rhinotracheale. The proportion of all for test-negative against both the two diseases was $81 \%$. Table 1 shows the estimated seroprevalence against avian pneumovirus among the study broilers categorized by farms. The numbers of broilers sampled between the 17 study farms were varied from 30-224. Thirteen out of the 17 farms had AP of greater than $0 \%$, between 0.4 and $81 \%$. All the point estimates of TP by Bayesian inference were greater than $0 \%$. The APs of equal to $0 \%$ were adjusted greater by Bayesian inference. The Bayesian posterior sampling means for the $\mathrm{SeB}$ and $\mathrm{SpB}$, estimated from the study, were $97.3 \%(95 \% \mathrm{BCl}: 94.3-99.3 \%)$ and $98.7 \%(95 \%$ BCl: $97.8-99.4 \%$ ), respectively and the overall true seroprevalence TPB was $1.9 \%(95 \% \mathrm{BCl}:<1-7.4 \%)$ (Table 2). Table 1 also shows the estimated seroprevalence against Ornithobacterium rhinotracheale among the study broilers. Thirteen out of the 17 farms had AP of greater than $0 \%$, between 0.5 and $15 \%$. All the point estimates of TP by Bayesian inference were greater than $0 \%$. The APs of greater than $0 \%$ were adjusted lesser by Bayesian inference, while APs of equal to $0 \%$ were adjusted greater by Bayesian inference. The Bayesian posterior sampling means for the SeB and SpB, estimated from the study, were $97.4 \%$ (95\% BCl: $94.4-99.3 \%)$ and $98.4 \%(95 \% \mathrm{BCl}: 97.7-$ $99.0 \%$ ), respectively and the overall true seroprevalence $\mathrm{TP}_{\mathrm{B}}$ was less than $0.1 \%(95 \% \mathrm{BCl}: 0-<0.1 \%)$ (Table 2$)$.

\begin{tabular}{|c|c|c|c|c|c|c|c|c|c|}
\hline \multirow[b]{3}{*}{ Farm ID } & \multirow[b]{3}{*}{$\mathrm{n}$} & \multicolumn{4}{|c|}{ Avian pneumovirus (\%) } & \multicolumn{4}{|c|}{ Ornithobacterium ininotracheale (\%) } \\
\hline & & \multirow[b]{2}{*}{ AP } & \multirow[b]{2}{*}{$\mathrm{TP}$} & \multicolumn{2}{|c|}{$95 \% \mathrm{BCl}$} & \multirow[b]{2}{*}{ AP } & \multirow[b]{2}{*}{$\mathrm{TP}$} & \multicolumn{2}{|c|}{$95 \% \mathrm{BCl}$} \\
\hline & & & & Lower & Upper & & & Lower & Upper \\
\hline 1 & 91 & 81 & 83 & 74 & 91 & 1 & $<0.1$ & 0 & $<0.1$ \\
\hline 2 & 89 & 0 & 0.3 & $<0.1$ & 2 & 0 & $<0.1$ & 0 & $<0.1$ \\
\hline 3 & 79 & 3 & 1 & $<0.1$ & 5 & 15 & 14 & 7 & 23 \\
\hline 4 & 97 & 3 & 1 & $<0.1$ & 5 & 0 & $<0.1$ & 0 & $<0.1$ \\
\hline 5 & 100 & 0 & 0.3 & $<0.1$ & 2 & 1 & $<0.1$ & 0 & $<0.1$ \\
\hline 6 & 100 & 27 & 26 & 18 & 36 & 2 & $<0.1$ & 0 & $<0.1$ \\
\hline 7 & 100 & 4 & 2 & $<0.1$ & 7 & 1 & $<0.1$ & 0 & $<0.1$ \\
\hline 8 & 113 & 4 & 2 & $<0.1$ & 6 & 0.9 & $<0.1$ & 0 & $<0.1$ \\
\hline 9 & 111 & 7 & 6 & 1 & 12 & 5 & 0.2 & 0 & 3 \\
\hline 10 & 119 & 6 & 4 & $<0.1$ & 9 & 3 & $<0.1$ & 0 & 0.5 \\
\hline 11 & 200 & 5 & 3 & $<0.1$ & 7 & 0.5 & $<0.1$ & 0 & $<0.1$ \\
\hline 12 & 65 & 0 & 0.4 & $<0.1$ & 2 & 0 & $<0.1$ & 0 & $<0.1$ \\
\hline 13 & 224 & 0 & 0.1 & $<0.1$ & 0.8 & 4 & 0.2 & 0 & 3 \\
\hline 14 & 223 & 0.4 & 0.2 & $<0.1$ & 1 & 0.9 & $<0.1$ & 0 & $<0.1$ \\
\hline 15 & 30 & 10 & 7 & $<0.1$ & 21 & 0 & $<0.1$ & 0 & $<0.1$ \\
\hline 16 & 80 & 31 & 31 & 21 & 42 & 3 & $<0.1$ & 0 & $<0.1$ \\
\hline 17 & 40 & 15 & 13 & 4 & 26 & 3 & $<0.1$ & 0 & $<0.1$ \\
\hline
\end{tabular}

Table 1: Estimated seroprevalence against avian pneumovius and Ornithobacterium rhinotracheale in broilers in Uruguay

$\mathrm{n}$; Number of chickens sampled, AP; Apparent Seroprevalence, TP; True Seroprevalence, $95 \%$ BCl; Bayesian Credible Interval

Table 2: Estimated seroprevalence against avian pneumovirus and Omithobacterium rhinotracheale in broilers in Uruguay and its test

\begin{tabular}{|c|c|c|c|}
\hline & 5th percentile & Mean & 95th percentile \\
\hline \multicolumn{4}{|l|}{ Avian pneumovirus } \\
\hline Overall true seroprevalence $\left(\mathrm{TP}_{\mathrm{\theta}}\right)$ & $<0.001$ & 0.019 & 0.074 \\
\hline Sensitivity $\left(\mathrm{Se}_{\mathrm{\theta}}\right)$ & 0.943 & 0.973 & 0.993 \\
\hline $\begin{array}{l}\text { Specificity ( } \mathrm{Sp} \text { ) } \\
\text { Ornithobacterium rhinotracheale }\end{array}$ & 0.978 & 0.987 & 0.994 \\
\hline Overall true seroprevalence $\left(\mathrm{TP}_{\mathrm{\theta}}\right)$ & 0 & $<0.001$ & $<0.001$ \\
\hline Sensitivity (Se日) & 0.944 & 0.974 & 0.993 \\
\hline Specificity (Spe) & 0.977 & 0.984 & 0.990 \\
\hline
\end{tabular}
characteristics 
Int. J. Poult. Sci., 9 (5): 490-494, 2010

\section{DISCUSSION}

This study represents a moderate-scale seroepidemiological investigation on avian pneumovirus and Ornithobacterium rhinotracheale of broilers in Uruguay. The results of this study indicated that the seroprevalence of avian pneumovirus and Ornithobacterium rhinotracheale antibodies is relatively low in the study broilers in the area. The observed individual seroprevalence of the antibodies in this study (1.9\% for avian pneumovirus and less than $0.1 \%$ for Ornithobacterium rhinotracheale) was lower than that reported by other authors in Argentina where the infection of these diseases was recently observed (Uriarte et al, 2010). However, several factors were different between studies, including study area, study period and sample size. These variations between study designs make it difficult to extract generalizable explanations with regard to the prevalence of any particular infectious diseases. Adjusted outcomes are required for accurate comparison of seroprevalence estimates. One of the aims of the present study was to illustrate how a hierarchical modeling approach permits the dependable estimation of the uncertainty corresponding an individual study's effect on outcome. The advantage of the approach used in the study was that outcome data from all studies could be incorporated in one coherent inference framework, including small samples. The hierarchical model data across all field studies to calculate the prevalence and $\mathrm{BCls}$ thus making relative assessment more robust, and more reliable (Dohoo et al., 2003). The methodology was useful for obtaining estimates of avian pneumovirus and Ornithobacterium rhinotracheale prevalence and for establishing prevalence distributions which could be used as input parameters in risk assessment and decision models. The Bayesian stochastic approach is more complexed but relatively easily can be performed in the freely available software WinBUGS. Its advantage is that, in addition to providing posterior distributions for the $\mathrm{TP}_{\mathrm{B}}$, it also provides posterior distributions (estimates) for $\mathrm{Se}_{\mathrm{B}}$ and $\mathrm{Sp}_{\mathrm{B}}$. However, knowledge and assumptions on the prior shape, value range and initializing values of the model inputs are needed.

\section{ACKNOWLEDGEMENTS}

This study was carried out as part of the project for the capacity development for improvement of livestock hygiene in the southern part of South America through regional cooperation [commonly known as: Proyecto de desarrollo professional continuo para los veterinarios del Sur (PROVETSUR)], funded by the Japan International Cooperation Agency.

\section{REFERENCES}

Baadsgaard, N.P. and E. Jogensen, 2003. A bayesian approach to the accuracy of clinical observations. Prev. Vet. Med., 59: 189-206.
Bisgaard, M., A.M. Bojesen, J.P. Christensen, P. Mark, F.M. Paul, M.B. Janet and J.A. Dennis, 2008. Infections caused by species of Pasteurellaceae, Ornithobacterium and Riemerella: An introduction. In: Poultry Diseases, 6th Edn., W.B. Saunders, Edinburgh, pp: 146-148.

Cook, J.K.A., 2000. Avian pneumovirus infections of turkeys and chickens. Vet. J., 160: 118-125.

Cook, J.K.A. and D. Cavanagh, 2002. Detection and differentiation of avian pneumoviruses (metapneumoviruses). Avian Pathol., 31: 117-132.

Cook, J.K.A., C.A. Dolby, D.J. Southee and A.P.A. Mockett, 1988. Demonstration of antibodies to turkey rhinotracheitis virus in serum from commercially reared flocks of chickens. Avian Pathol., 17: 403410.

Dohoo, I., W. Martin and H. Stryhn, 2003. Veterinary epidemiologic research. 1st Edn., AVC Inc., Prince Edward Island, pp: 706.

FAO, 2010. FAOSTAT. Rome. Available from: http://faostat.fao.org/.

Giossa, G., K. Suzuki, M. Petruccelli, G. Rodríguez, G. Trenchi and H. Trenchi, 2010. Flock-level seroprevalence against avian pneumovirus amongst Uruguayan broiler chickens. Int. J. Poult. Sci., 9: 217-220.

Gough, R.E., 2005. Poultry: Avian pneumovirus, In: Kahn, C.M. (Ed.), The Merck veterinary manual, 9th Edn., Merck and Co., Whitehouse Station, pp: 2299-2300.

Hintze, J., 2008. PASS 2008 software. NCSS, Kaysville, UT.

IDEXX, 2003. IDEXX ORT Test Kit detects all serotypes in chicken and turkey serum. Animal Health Updates. Available from: http://mww.idexx.com/ pubwebresources/pdf/en_us/livestock-poultry/ 0962896.pdf.

IDEXX, 2004. Effective tool for monitoring avian pneumovirus in chicken and turkey flocks. Animal Health Updates. Available at: http://muwidexx. com/pubwebresources/pdf/en_us/livestockpoultry/6478800m.pdf.

Lunn, D.J., A. Thomas, N. Best and D. Spiegelhalter, 2000. WinBUGS - a Bayesian modelling framework: Concepts, structure and extensibility. Stat. Comput., 10: $325-337$.

Ministerio de Ganadería Agricultura y Pesca, 2010. Division Contralor de Semovientes (DI.CO.SE.), Unidad de monitoreo avicola. Available at: http://Wwn.mgap.gub.uy/dgsg/DICOSEJUMA/UMA. htm.

Rogan, W.J. and B. Gladen, 1978. Estimating prevalence from results of a screening-test. Am. J. Epidemiol., 107: 71-76.

Suzuki, K., M. Petruccelli, G. Trenchi, G. Giossa, G. Rodriguez and H. Trenchi, 2010. Flock-level seroprevalence against Ornithobacterium rhinotracheale among broilers in Uruguay. Int. J. Poult. Sci., 9: 167-170. 
Uriarte, J., K. Suzuki, J. Origlia, D. Gornatti, M. Piscopo, R. Cerda, M. Herrero, H. Marcantoni, M.F. Unzaga, E. Spinsantti, F. Marino, M. Pecoraro, S. Corva and M. Petruccelli, 2010. Stochastic estimation of seroprevalence against Ornithobacterium rhinotracheale and avian pneumovirus among chickens in Argentina. Int. J. Poult. Sci., 9: 352-356.
Van Empel, P., P. Mark, F.M. Paul, M.B. Janet and J.A. Dennis, 2008. Ornithobacterium rhinotracheale. In: Poultry Diseases, 6th Edn., W.B. Saunders, Edinburgh, pp: 164-171.

Vose, D., 2008. Risk analysis: A quantitative guide, 3rd Edn., Wiley, Chichester, pp: 752. 